\title{
English Vocabulary Learning Through Form-Focused Approaches Using Video Podcasts
}

\author{
Sidra Khan $^{1^{*}}$ Dr. Shabana Sartaj ${ }^{2} \quad$ Sadia Memon $^{1}$ \\ 1.English Language Development Centre (ELDC), Mehran University of Engineering \& Technology, Jamshoro \\ 2.Sindh Agriculture University, Tandojam
}

\begin{abstract}
The objective of this study was to determine whether the lectures given to English students as a foreign language in addition to regular classes, would enable them to grow their language skills and to review and find information on podcasting as a learning or teaching tool, in order to improve comprehension and learning methods. Since the arrivals of the digital era, audio media utilization in teaching language has become easier to use. It goes online through the use of websites, online learning environments, learning management systems and podcast. So, this study focuses on the examination of shape-oriented methods when taking video podcasting into account. The study focuses primarily on Pakistan analyzing English language learning activities in Pakistani universities, as university graduates have been taken as a model. As technical developments affect all other industries, they also affect the education market. However, these developments are not mainly followed in developed countries such as Pakistan and Pakistani universities still adopt the conventional methods of education. As discussed above, studying has become exciting for students around the world as teachers bring some fascinating and advantageous technology such as video podcast into the classroom. This study assesses, thus, the effects of English vocabulary learning by using video podcasts to use form-focused approaches.

Keywords: Vocabulary Teaching Approaches, Focus on Form vs Focus on Forms, Usage of Technology, New ways of Learning Vocabulary vs Traditional

DOI: $10.7176 / J L L L / 78-04$
\end{abstract}

Publication date: April $30^{\text {th }} 2021$

\section{Introduction}

The word form focused approaches is described as any scheduled or incidental education to enable language students to reflect attention to the form of language. It is a common term for analytical education, forms emphasis and corrections (Schenck, 2018). The word form-oriented education is used to describe both methods of teaching based on artificial syllabuses, as well as more communication methods in which commitment to form is derived from mostly meaning-oriented practices (Miyamoto, 2017).

New technologies have provided many implications to the language learning due to the high-tech development and the evolution of language learning. The implications work both on the view of educators and students (Kisselev, Dubinina \& Polinsky, 2020). Educators agree that the use of new technology help them a lot in their profession. In addition, students have the same feeling that learning with the implementation of new technology has become more engaging and fun (Piggott, 2019). The use of technology in language learning may vary, for instance, as a media for teaching and learning language. One of the most influencing media in language learning is audio media. Traditional audio media formats such as vinyl, cassettes, CDs and DVDs have been used for decades (Storch, 2018). Researchers agreed that its implementation in language learning gives many benefits both for teachers and students. The benefits mostly come from its practical use that makes language learning easier and more satisfying (Alahmad, 2019). Furthermore, as the technology continues to develop, the use of audio media in language learning becomes more satisfying. Since the arrivals of the digital era, audio media utilization in teaching language has become easier to use. It goes online through the use of websites, online learning environments, learning management systems and podcast (Curado Fuentes, 2017).

The goal of this study was to decide whether the lectures given in addition to standard courses to English students as a foreign language help them develop their language skills and to examine and find knowledge about the adoption of podcasting as a medium for learning or teaching, with the aim of enhancing comprehension and learning methods. However, this research is specifically focusing on the assessment of form focused approaches while considering the use of video podcast. The research is precisely focused on Pakistan evaluating the practices of English vocabulary learning in universities of Pakistan as undergraduate students were taken as sample for the research.

\subsection{Aim and Objectives}

The core aim of the research is to determine the ways in which Form-focused Approaches facilitates English Vocabulary Learning using video podcasts. Whereas the key objectives are:

- $\quad$ To assess the impact of Form-focused Approaches on English Vocabulary Learning

- To evaluate the benefits of Form-focused Approaches using video podcasts 


\subsection{Research Questions}

following are the main research questions:

- How Form-focused Approaches influence the English Vocabulary Learning?

- What are the benefits of Form-focused Approaches using video podcasts?

\subsection{Significance of Research}

As the technological advancement is affecting every other industry so it also has impacts on educational sector (Scotland, 2021). However, in developing countries like Pakistan such advancements are not dominantly practiced and Pakistani universities are still following the traditional ways of learning. As mentioned above, learning has become a fun activity for the students around the world when the teachers add some interesting and beneficial technologies to the classroom such as video podcast. This research is therefore assessing the benefits that students can have in English vocabulary learning when form-focused approaches are applied using video podcasts. The findings of this research are important for the undergraduate students in Pakistani universities. the manufacturing sector today, human capital is still essential for most factories to carry out a variety of manual operations, in spite of the rapid advancement of automation technology and robotics. Futuristic vision of "unmanned manufacturing" (Deen 1993) is forbiddingly expensive, because all its hardware components need to be computer controlled so as to freely communicate with each other; and yet, most of the outcomes are not promising (Sun \& Venuvinod 2001). By and large, factories equipped with relatively simple machinery controls will require continuous attendance of human operators; for examples, textile mills, leather products, and medical appliances. With limited capital investments in production equipment, the main budget of their fixed costs lies on the workforce size (Techawiboonwong et al. 2006).

With regard to cost-effectiveness, labour planning always opts for the minimum number of workers needed to deal with the daily operations, as well as the probable rate of disturbance (Lim et al. 2008). The workforce disturbance is often ascribed to absenteeism and turnover, which may result in considerable loss of productivity for any labour-intensive division (Easton \& Goodale 2002). Buffering with redundant skilled workers (Molleman \& Slomp 1999) or relief workers (Redding 2004) might be a direct solution to absenteeism; however, the rising labour cost must be justifiable due to the fact that underutilisation of labour during low demand seasons is considered a waste of resources. Absenteeism is the measure of unplanned absences from workplace due to some reasons like personal emergency, accident, illness, etc. Turnover occurs when an active worker resigns from the company of his own accord, thus leaving a vacant post until a replacement is found. If such disturbance has caused a large number of tasks become unattended and overdue, the company is then vulnerable to overtime cost, shrunk capacity and productivity, extra queuing time, lost business income, etc. In order to prevent these deteriorative effects, optimising the number of workers can be helpful. As a fundamental branch of knowledge in manufacturing business, workforce management will never fall behind the times. Therefore, it is worth an attempt to incorporate a novel methodology, such as HMS, into the state of the art of workforce sizing.

\section{Literature Review}

\subsection{Importance of English Vocabulary Learning}

A language teaching approach that stresses the learning of language types including lexical characteristics, phonemic characteristics, grammatical structures, etc. (Zhang et al., 2017). In foreign language instruction, vocabulary plays a key role. Vocabulary has an unavoidable function in the study of a foreign language. According to Asyiah, (2017) a rich vocabulary can fully enable English students and their four key skills to listen, communicate, learn, and write. Perfecting in vocabulary ensures that students are well informed of the meanings, the expression, the written form, the grammatical behavior, the word derivation, the word conjunction, the word $\log$ written and spoken, the connotation, the associations of the word and the intensity of word (Zou \& Zhou, 2017). Practitioners have been unable to take into account the instruction of vocabulary and vocabulary in foreign languages in relevant research on vocabulary expectations and vocabulary education. Asyiah, (2017) showed that most students and teachers lack proper knowledge of instructional techniques and vocabulary learning strategies. The value of vocabulary and vocabulary learning techniques remains unknown to teachers and the vocabulary strategy is not integrated in the program.

English was one of the traditional ways of returning to the general public and mass. Afzal, (2019) provided that media buzzwords and registries are not easy to tackle and in media research, vocabulary is a crucial challenge. A robust wording enhances hearing, chatting, reading and writing in all fields of communication. Afzal, (2019) added that for these purposes, vocabulary is essential to the development of a child: Vocabulary makes kids learn about the universe and know the environment. The expansion of a child's word awareness requires unrestricted access to new material. Awareness of the English language relies on the second and international linguists and even the native speakers' knowledge of their vocabulary (Mokhtar et al., 2017). While vocabulary learning is important, it raises a variety of problems for non-native English students in particular. Individuals with good levels of language skills, linguistics, literature and comprehension have poor academic 
success in various classes at the university's education level. Afzal, (2019) illustrates the value of studying English, draws learners' attention to it, illustrates students' challenges and increases knowledge of their vocabulary. Future studies should investigate the experiences of teachers on vocabulary issues and strategies for teaching vocabulary in English language classrooms (Hao et al., 2019).

The word language has a wide range of instructor definitions. Some people consider it sight-word vocabulary as the students' instant acknowledgement of words. Widyastuti \& Kusuma, (2019) define it as meaning-vocabulary expressions describing the words understood by pupils and also as hearing-vocabulary or comprehension of the words heard and spoken by students. It is defined by the content teachers as an academic vocabulary that represents the vocabulary or the understatement of oral and printed language in the text. A variety of definitions of the word vocabulary suggested by students (Chen, Chen \& Yang, 2019). Some people consider it sight-word vocabulary as the students' instant acknowledgement of words.

\subsection{Form Focused Approach}

Form Focus is a language learning technique, in which students become conscious of the linguistic form of language elements which they can already communicate with (O'G'Li \& Muzaffarovna, 2019). Focus on Form is all about the emphasis on forms, is compared with the focus on language-feature explicitly and the concentration on interpretation is restricted to meaning without any formal focus. According to Schenck, (2018) In order for a teaching intervention to count as a form emphasis and not a form focus, the learner must know the meaning and usage of the language characteristics prior to acquiring the formula. In 1988 Michael Long suggested to focus on the form. Miyamoto, (2017) provided that based on FonF-based instruction's efficacy in its potentials of incidental and expected L2 learning, the FPP (form-oriented) practice model was developed and contextualized. In order to account for nonlinear and complex motivating variables of the students, the FonF practice model has proven successful at the person level and utilizes CALL to improve speaking and listening skills (Kisselev, Dubinina \& Polinsky, 2020).

The definition of formal emphasis was motivated by the lack of data, on the one hand, that forms are a centre of interest and, on the other, that language learning has strong advantages over inexperienced learning. In a literate sample, learning considered a significant advantage relative to learning unlearned to learning in both the rate of learning and the ultimate level of training. Piggott, (2019) mentioned that the idea of form emphasis was inspired by, on the one hand, the lack of evidence for the effectiveness of focusing on forms and, on the other, obvious advantages of instructed language learning over untrained education. Long considered a distinct benefit to learnt in both the pace of learning and the ultimate standard of education in a literary study compared learning with unlearned language learning.

Storch, (2018) provided that the definition can be split up into two ideas that illustrate the concept of focusing on shape more clearly: focusing on shapes and focusing on context on the basis that they concentrate primarily on structure. According to Alahmad, (2019) the emphasis is on structure and the focus is on meaning. Forms corresponds to the standard approach, which specifically teaches only linguistic forms without dialogue and substantive information. Forms are the main focus on grammar translations and audio-lingual approaches. Curado Fuentes, (2017) added that the first method of grammar translation was used to gather information and skills from Latin and Greek written texts, so it was not necessary to speak and listen. Furthermore, the key focal points of this approach are phrase-level grammar rules, and conversion from a target language to L2 (Scotland, 2021).

Contrary to some authors, both emphasis on modes and focus on meaning are questionable. They also advocate these two main methods. With regard to formalities, students only need to collect discrete grammar objects without using a correspondence language, and thus, communicative competence is not improved (Oba, 2019). No form-based instruction nor meaning-based instruction will lead to a full learning of the foreign language. As per Elgort et al., (2018) to address the problems addressed in previous methodologies, the priority is placed on formal approach such that the emphasis on interpretation is retained when grappling with the shortcomings of a conventional approach to types. The distinction between formula and form: the emphasis on formula is that, as students come up by the way in lessons whose key focus is interpretation or communication, they obviously attract exposure to language influences (Afshar, 2021).

Emphasis on form sometimes entails the instructor and/or one or more students turning their focus sometimes to the linguistic code characteristics due to suspected problems of understanding or development. According to Franciosi, (2017) This is the same as when native speakers who are successful authors stop taking into account the required address for writing a letter to a foreign person and when effective readers abruptly disconfirm a theory while reading and are briefly forced to trace their steps in a document before the item is located. Sensibility and coordination are the normal and basic orientation (Ma, 2017).

\subsection{English Vocabulary Learning and Form Focused Approach}

According to the study by Lee, (2019) because of the increased globalization and software development growth, 
English has become an essential tool for communication, collecting information and performing businesses with people from different countries. In this regard, the speakers must improve their future prosperity by enhancing their skills in communication and consistency in English. Shape centered approach encompasses both conventional teaching methods focusing on structural instruction and more communicative approaches where exposure to form comes from mostly meaning driven practices. It refers to any proposed or by-product educational activity designed to encourage language learners to pay attention to language (Elgort, 2017).

The emphasis on systematic methods, using the strategies, tends to increase the accuracy of students in meaningful schooling. Instruction promoting a systematic, non-interfering emphasis on shape induces a quicker pace of analysis and certainly higher level of SL than form-focused instruction (González-Fernández \& Schmitt, 2017). The fact that it has a positive effect on long-term precision of linguistic forms provides another addition to the emphasis on form. Rodgers \& Webb, (2020) claimed that focusing on form has a positive effect on teachers who teach English in EFL environments. Focusing on shape is easier than focusing on context so mistakes can be correctly corrected by students. The students are introduced to practical contributions and contact options under the guidelines of this strategy (Viera, 2017). Using form-based instruction rather than CLT is more useful to improve precision than meaning-based instruction alone. Teachers need those pedagogical options to optimize the benefit of the emphasis on type according to their teaching contexts and their student characteristics.

\subsection{Video Podcast and English Vocabulary Learning}

In the classroom, technology becomes even more necessary. According to Woottipong, (2017) social networks have become common, and our use of technology has changed our way of life totally. Moodle is an easy to use and highly scalable free open source software framework. Teachers are able to arrange, administer, and provide courses through chats and forums, tasks, quizzes, lecture notes and interactive tools of any kind, including graphics, video, or audio. Al-Ahdal, (2020) added that use of digital resources to create attractive experiences promote student learning and inspire pupils. As with Moodle, podcasts have become highly popular in education. Yi-qiu, (2018) provided that this study tool has demonstrated versatility and allows students to monitor their own learning rates when watching or listening, thus generating freedom of learning. Podcasts also improve awareness of subjects and assist students in analyzing content. Woottipong, (2017) also clarified that teachers could use podcast as an important instructional tool by posting podcast conferences to websites in the classroom and allowing their students to access the websites. Learners can boost their studying by online podcasts or downloaded podcasts, which can be accessed later outside the class. Shahid \& Ali, (2018) mentioned that podcast tutorials may also be used to help students review courses, which are useful for English as a foreign language (EFL) student. Since podcasting is an emerging mobile application, just a few previous studies on quality standards in the successful use of podcasts in a teaching sense of foreign languages. Studies say strongly that the most effective way to help grammar students develop their writing is to use written students as a base for grammar discussion (Sodikin, 2020).

Killingback, Ahmed \& Williams, (2019) provided that present use of podcasts as a new medium for feedback information actually promotes listening understanding and has thus enhanced target language acquisition. The post-test control group of the video-podcast group was slightly above performance. The results suggest that video podcasts are a helpful means to improve the listening understanding of the EFL students. Dmytriieva, (2018) addresses the question of English teaching by podcasts. The theoretical resource analysis showed that the use of podcasts is a creative and successful way of English learning in the light of the rapid proliferation of modern high-tech software to millennial population. According to Yugsán-Gómez et al., (2019) podcasts for video and audio education improve the awareness of students and further conversation, increase incentive for students to learn, facilitate efficiency in education, strengthen the reading resources to offer additional knowledge and serve as an important new experience at school and at home.

\section{Methodology}

To conduct the research, it is important to decide for the appropriate research approach. For this analysis, a quantitative approach was used as a research design. This research used a quasi-experimental design focused on the values and interpretations (Mokhtar et al., 2017). The quasi-experimental architecture of the study was used since the data collection was carried out in common university contexts. The advantage of using this design is that the external validity is more expected to follow through with the normal educational circumstance (Hao et al., 2019). Unlike typical experiments, the language input generally involves the text read or written input. This research has incorporated video podcasts in an audiovisual way. Newscast episodes from the British BBC Night Bulletin service were used via a multimedia interface and a pair of speakers connected to the laptop of the lecturer during the lecture. 


\subsection{Data Collection}

The sample size for this research is 80 including male and female undergraduates from Mehran University of Engineering and Technology and the age group chosen for this is 19 to 22. It is important to have students above the intermediate level of aptitude. A paper-based assessment was therefore conducted for a more accuracy ranking and all scores in four intact groups were originally nominated for the analysis in order to cover a sufficient subject pool, within one standard deviation above and below the mean ( $\mathrm{SD}=18.32, \mathrm{M}=541)$.

A vocabulary level test was also used to further test lexical skills (Widyastuti \& Kusuma, 2019). The test was offered at 5000-word stages, in which those above 24 qualified in a 30-point test (one point was allocated to each item). Highly trained topics were chosen to handle the highly advanced newscasts' vocabulary. Finally, following qualified to proceed other assessment sessions for next 1 month;

- $\quad 2$ FonF groups with input enhancement $(n=15)$ and production $(n=21)$

- 1 FonFs group with task-related $(\mathrm{n}=22)$

- $\quad 1$ MF group with control $(\mathrm{n}=22)$

The learners, study in 4 intact classes of English language and literature. The instructor - one of the writers of this report - succeeded in implementing the planned instructional procedures with the courtesy of its professors who dispersed the classes some minutes early for our experiment. The students have cooperated entirely as the novelty of the news casts encouraged them to go past their timeframe for a few extra minutes.

\subsection{Data Analysis}

Notwithstanding some longitudinal studies in the FFI, there was no concern for shaping instructional outlines. The two genuinely trustworthy FonF exhibitions are among input-based choices, output based (created) choices, Clear choices and corrective responses, and improved conditions for development and input. However, the dominance of grammar and the degree of which vocabulary are seen as a new foundation goes mostly through this overwhelming stance. The following two education processes are illustrated in this research:

Input improvement is Sharwood Smith's (1993) first case instructional model that refers to the prudent treatment of the input pupils. These students are exposed to increase student awareness and understanding. The organizational characteristics of the feedback endorse it such that the anticipated teachers have taken topographies to the pupils. Procedures such as typographies, gestures, separate pressure, intonation, and nonlinguistic signals are among those practices that can emphasize language input to allow students to take it into account.

Founded production FonF focuses on instruction that enables or encourages students to speak in a target framework. In this technique, the then subtle attention of the student is centered by production methods on particular features of the input. The action of language processing reassesses the students' ability to speak, which ultimately increases the chances for the students to actively conduct their own words and words in the target language. It is remembered, however, that there needs to be an appropriate allocation of deliberate resources focused on the type and not overburdened during the process of input and output.

In particular, an average is calculated by multiplying the total score of students from the five successful vocabulary tests, to make one single representative score. This method is often carried out with late vocabulary and understanding assessments independently. SPSS data constructed on version 21.0 will be reviewed for the submission. At the .05 degree of relevance, single-way ANOVA and F-test shall refer to questions of study. For the understanding of routine performance and distribution of their markings for each component it will be used the description statistical parameters (mean and standard deviation). In order to analyze the changes in the four teaching conditions, the data will then be provided to a MANOVA.

\subsubsection{Sampling}

The research participants are English students of both genders from the community eligible. A sample of 80 students from the first year B.E and their English course is held at the MUET, Jamshoro. Their language course is functional. The research participants are Hyderabadi and Urdu/Sindhi are their mother tongue. Participants were usually divided into four classes, including two categories FonF (Input Enhancement and Creation), one category FonFs (task-based) and a five weeks training course for MF (control). Four group findings were confirmed by the Data Set. In order to ensure that all four types are similar in their general English proficiency, a proficiency test previously developed by the Oxford University and the Cambridge University standard placement assay (2001).

\subsubsection{Instruments}

The four criteria of therapy covering a total of three individual counseling sessions that included mini lessons conceived by the teachers have included six five-point (3 vocabulary and 3 understanding) assessments. Weekly meetings were organized for various courses and organizations, but the following language and understanding were the same. One instant recall of vocabulary and an understanding test planned by the instructor were given to the students at the conclusion of each lesson, accompanied by a delayed post-test vocabulary administered a week later. The topic of understanding consisted of true/false elements depending on the quality of a newscast. 
With respect to the construction of test objects, the instructor submitted a set of 5item active call back vocabulary testing as the exercise included the performance assessments of active lexical awareness. The instruments were tested for the reliability of measurements with less than 10 components using median interposition correlations. The means for interpretation and vocabulary assessment is well above the standards proposed (.20 to .40$)$. Either .60 or .70 were both inter-item correlations. Only the medium of understanding measure 1 , which was .50 , was the case. To ensure the understanding and vocabulary checks are valid, we used expert judgements. The four judges had been lecturers for at least five years at the same university, where data were gathered. A successful vocabulary alert is calculated by giving the form to a specific meaning or definition; the first letter of the specified word is thus provided to avoid non-target terms from being delivered by the learner. Each correct reply earned one point, one incorrect response or no reaction, and half a point was assigned to an incorrect or rough reply.

\section{Methodology}

\begin{tabular}{|c|c|c|c|c|}
\hline $\begin{array}{c}\text { Dependent } \\
\text { Variable }\end{array}$ & F & dfl & df2 & P \\
\hline Word recall & 1.911 & 3 & 84 & .119 \\
\hline Word retention & 1.826 & 3 & 84 & .119 \\
\hline Comprehension & 1.776 & 3 & 84 & .158 \\
\hline
\end{tabular}

\section{Table 1. Levene's Test for Equality of Variances}

In the three immediate vocabulary assessments, mainly the cumulative number of student scores was summed to provide a single representative scoring. This was also provided independently for the delayed vocabulary and understanding studies.

Table 1 shows no substantively different category variances in terms of recollection of words (immediate), retrieval of words (deferred recall) and understanding of texts and thus fulfills expectations about the equivalent status of variances $(\mathrm{p}>0.05)$.

\begin{tabular}{|c|c|c|c|c|}
\hline Source & Dependent Variable & F & P & Partial n2 \\
\hline Method & Word recall & 184.74 & .000 & .868 \\
\hline & Word retention & 39.84 & .000 & .587 \\
\hline & Comprehension & 6.96 & .000 & .199 \\
\hline
\end{tabular}

Table 2. Tests of Between-subjects Effects

\begin{tabular}{|c|c|c|c|}
\hline Method & Mean & SD & $\mathrm{N}$ \\
\hline Input-based FonF & 4.63 & 0.54 & 15 \\
\hline Out-based FonF & 4.71 & 0.46 & 21 \\
\hline Task Related & 3.96 & 0.89 & 22 \\
\hline MF Control & 0.77 & 0.57 & 22 \\
\hline Total & & & 80 \\
\hline
\end{tabular}

Table 3. Descriptive Statistics for Immediate Recall

The findings shown in Table 2 show that the three dependent variables of phrase reminder, word retention and understanding of text are influenced substantially by instructional procedures at a $95 \%$ confidence interval. In at least two of the processes, the group means would then have been substantially different. In general, the effect size index indicates that the educational processes had an impact on the active term recall of 86.8 per cent and an impact of 58.7 per cent on the postponed work. In the meantime, the impact on understanding of the students as a whole was a minimum of $19.9 \%$.

In view of the first issue of study, Table 3 shows descriptive figures about how diverse approaches to teaching influenced the immediate retraction of vocabulary items by our participants. It should be noted that values of the mean column on all the tables (immediate reminders, delayed recalls and understandings), on the basis of the number of correctly answered questions, indicate test scores of the apprentice between 0 (minimum) 
and 5 (maximum). The information was given in order to test variations in the four training conditions for a multidisciplinary study of variance (MANOVA). The MANOVAS showed that the three form-focused approaches and the control group, $\mathrm{F}(3,84)=184,74, \mathrm{p}<, 001$ were significantly distinct.

\begin{tabular}{|c|c|c|c|c|}
\hline \multirow{2}{*}{ Method } & \multirow{2}{*}{ N } & \multicolumn{3}{|c|}{ Subset } \\
\cline { 3 - 5 } & & 1 & 2 & 3 \\
\hline MF Control & 22 & 0.77 & & \\
\hline Task-related FonFs & 22 & & 3.96 & \\
\hline Input-based FonF & 15 & & & 4.63 \\
\hline Output-based FonF & 22 & & & 4.71 \\
\hline P & & 1.00 & 1.00 & 0.98 \\
\hline
\end{tabular}

\section{Table 4. Subsets for Immediate Recall}

For multiple comparisons of our instructional approaches, subsequent TUKEY assessments (see Table 4) have demonstrated a considerably higher degree of improvements for the students under the conditions FonF (task related) and FonF (output dependent and input based) than the MF community, with their successful vocabulary recall. In the other hand, it can be shown that in FonFs, both of the FonF groups have outdone their equivalents reliably and substantially.

\begin{tabular}{|c|c|c|c|}
\hline Method & Mean & SD & N \\
\hline Input-based FonF & 2.31 & 1.13 & 15 \\
\hline Out-based FonF & 3.87 & 1.18 & 21 \\
\hline Task Related & 1.32 & 1.44 & 22 \\
\hline MF Control & 0.42 & 0.48 & 22 \\
\hline Total & & & $\mathbf{8 0}$ \\
\hline
\end{tabular}

Table 5. Descriptive Statistics for Delayed Recall

\begin{tabular}{|c|c|c|c|c|}
\hline \multirow{2}{*}{ Method } & \multirow{2}{*}{$\mathbf{N}$} & \multicolumn{3}{|c|}{ Subset } \\
\cline { 3 - 5 } & & 1 & 2 & 3 \\
\hline MF Control & 22 & 0.42 & & \\
\hline Task-related FonFs & 22 & 1.32 & & \\
\hline Input-based FonF & 15 & & 2.31 & \\
\hline Output-based FonF & 21 & & & 3.87 \\
\hline P & & 0.06 & 1.00 & 1.00 \\
\hline
\end{tabular}

Table 6. Subsets for Retention (Delayed Recall)

The values of standard deviation and mean for the delayed call are given in Table 5 of the second research issue. Again, the highest average score is found in FonF (production = 3.87, entrance-based = 2.31). MANOVA also observed statistical variations in this step between our training classes, $F(3,84)=39.84$, $p<001$. Tukey posthoc analyses did not show that the FonF and the MF (control) groups had any major differences. Since no clear advice was taken in the control group during the treatment, it can be deduced that task-related FonFs are less effective in remembering vocabulary for students in the long term. The two major FonF situations also vary in that the manufacturing community has greatly outstripped the Input Improvement group as in Table 6. 


\begin{tabular}{|c|c|c|c|}
\hline Method & Mean & SD & $\mathrm{N}$ \\
\hline Input-based FonF & 4.33 & 0.61 & 15 \\
\hline Output-based FonF & 4.38 & 0.57 & 21 \\
\hline Task Related & 3.45 & 0.65 & 22 \\
\hline MF Control & 3.86 & 1.09 & 22 \\
\hline Total & & & 80 \\
\hline
\end{tabular}

Table 7. Descriptive Statistics for Text Comprehension

\begin{tabular}{|c|c|c|c|}
\hline \multirow{2}{*}{ Method } & \multirow{2}{*}{ N } & \multicolumn{2}{|c|}{ Subset } \\
\cline { 3 - 4 } & & 1 & 2 \\
\hline MF Control & 22 & 0.42 & \\
\hline Task related FonFs & 22 & 1.32 & \\
\hline Input-based FonF & 15 & & 2.31 \\
\hline Output-based FonF & 21 & & \\
\hline$p$ & & 0.06 & 1.00 \\
\hline
\end{tabular}

\section{Table 8. Subsets for Text Comprehension}

Finally, it is time to answer the third issue on the effectiveness of the various learner understanding education protocols (see Table 7 for descriptive statistics). At these times the MANOVA run showed that the three ( 2 FonFs and FonF) classes did not differ substantially from the control group $\mathrm{F}(3,84)=6.96, \mathrm{p}<001$, respectively. It may also be mentioned that none of the three approaches substantially influences the interpretation of newscast material by students. The post-hoc test (Table 8) nevertheless demonstrated that the only observed confusion lies between the FonFs condition yet the other FonF conditions under which the FonFs group, both input and output dependent, outdid the FonFs Group relevant to the tasks. Figure 1 shows the standings of the four therapy conditions.

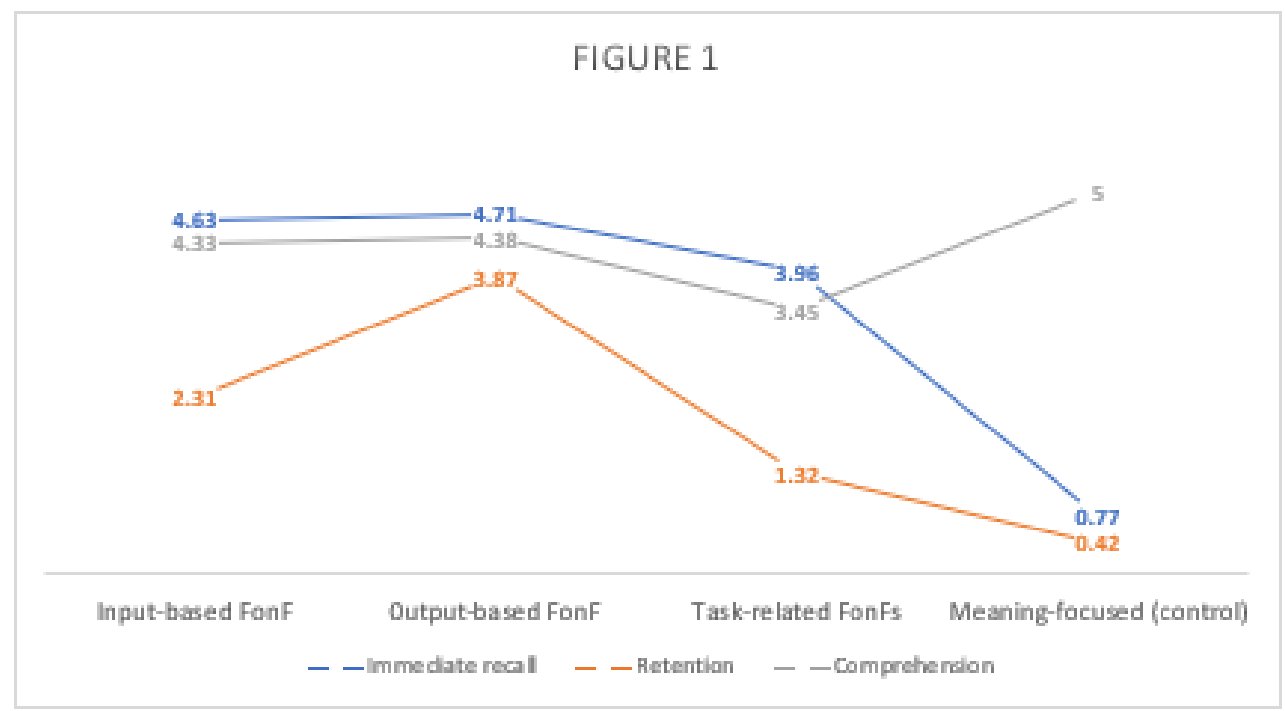

Figure 1. Comparative Results are shown for Immediate Recall, Delayed Recall (of vocabulary), and Text Comprehension acrogs the four conditions.

\section{Discussion}

The aim of this thesis was to figure out what kind of structured lexical instruction works better while exploring how FFI protocols influence the understanding of students. A brief analysis of the results shows that there have 
been greater improvements from the two FonF protocols. Regarding the immediate test of the target terms, both FonFs and FonF methods have been able to help students, much better than their MF equivalent, to remember vocabulary objects. The only way to say would not lead to beneficial lexical growth would be to merely expose L2 without FFI, as is seen in MF Community. It's because students primarily use the plot in the text instead of disrupting the unfamiliar vocabulary objects. But as they find that, with the massive and continuous flow of input data, it is not always easy to grasp or process what the new terms represent (Al-Ahdal, 2020). This tends to conform to the literature's previous observations regarding FFI and non-FFI functions.

As a 'efficiency instruction' our first research question tackled the greatest improvements, namely in the immediate reminder, in the development and feedback of FonF protocols. The students in the output community had to reconstruct in collaboration the words containing or contextualizing the target words in the input. This illustrates the effectiveness of restoring tasks that help to understand the void in the targeted type (Yi-qiu, 2018). These tasks optimize the similarity between the output of the learner and the TL model. It is also proposed that the appropriate task characteristics be added for feedback in order for the warning and learning of a particular type this has been achieved in our experiment. L2 pedagogy research recently promotes the use of assignments that enable students to collaboratively generate results. Tasks that encourage learners to produce language and reflect on their form can be designed (Shahid \& Ali, 2018). When the challenge is designed to get students to speak about the language they produce, their speech will serve their language knowledge.

In addition, the input-based guidance or input-enhancement technique was often used to encourage the acquisition of notices and assistance (Woottipong, 2017). When the input-based instruction clarifies the context of a target structure, it is so efficient and in some situations much more effective than explicit instruction. Sometimes it is not strictly mandatory for students to create a grammatical structure to obtain it. Input-based teaching will thus benefit if new language features are to be taught (Dmytriieva, 2018).

The analytical results also favor the FonF protocol over FonFs. In terms of immediate use of the words all FonF conditions $(\mathrm{M}=4.71$ in the output group and 4.63 in the input group) have greatly changed than FonFs (M = 3.96). In FonFs, vocabulary can be distorted at the level of the sentence rather than the level of the discourse. In the latter example, parallels in both prior and subsequent phrases are taken, rather than particular phrases in isolation (Yugsán-Gómez et al., 2019). The emphasis on contrasting interpretation and discreet context-free language analysis appeared to be unable to quantify FonF behaviours usually extending beyond the level of isolated sentences and using a contextual relevance in order to generate learning.

The second issue of study aimed at measuring the longevity of FFI treatment forms by using delayed posttests as a building block to ensure the external validity of an FFI study. Of interest, the same situation has behaved almost the same with the delayed reminder of terms, giving the FonFs a further blast. This time around, FonFs showed that it would be substantially and perhaps shockingly counterproductive to increase word retention after a week's practice $(\mathrm{M}=1,32)$. FonF processes have seemed to have succeeded in leading into a more elaborate method with both their significances and context-oriented attributes $(\mathrm{M}=3.87$ in the output group and $\mathrm{M}=2.31$ in the input group). The performance status again confirms the argument of generative models that learners use, refresh or elaborate new knowledge to enhance their learning and retention. The opportunity for students to schedule performance seems to have enabled them to concentrate on shape and consistency spontaneously.

All in all, when the productive FonF role is contrasted with the input-based FonF, it can be argued that the former's advantages tend to be over the former, particularly as far as a delayed reminder of new terms is concerned (Yugsán-Gómez et al., 2019). Furthermore, literature indicates that different production tasks are considered to be more efficient than understanding tasks.

The library metaphor offers a convincing reason for FonF's popularity with FonFs. However, power is linked to the ability to use skills for a variety of particular activities, such as an effective purchasing of 2 fictitious books or a library novel in the Victorian era. Knowing the structure of a library is also one thing and it is another thing that is quickly and effectively used. For the system of mental expression, he maintains, the same point. Word knowledge or structure is not the ability to successfully create or interpret it. We assume that this metaphor should be generalized to take account of the conflict surrounding FonF and FonFs. In FonFs, you might very well know a single word owing to a wide variety of practices ranging from the contrast study of the text and the probability of exploring the etymology and usage of the word at the right time (Dmytriieva, 2018).

Although much neglected in various vocabulary experiments, the third completely critical research topic was the issue of awareness. Comparing the average scores of the control (MF) classes for the three FFIs, these methods have shown that no considerable obstacles are provided to keep students focused on textual understanding while being fully conscious and looking after new elements of vocabulary. Although average discrepancies between the four conditions were not substantial $(\mathrm{M}=4.38$ for the output group, 4.33 for the input group, 3.45 for the FonFs group, and 3.87 for the MF group), there was a significant differential between the FonFs group and the FonFs group that obtained the lower average results with an enclosed control group margin. This supports further the argument that, considering all the benefits associated with it in L2 research up to now, 
lexical Fonfs appear to be made to the detriment of the students' restricted understanding of textual material.

\section{Conclusion}

New innovations have already been developed in the field of education which has contributed to a new form of teaching. It is also supposed that teachers ought to take a few steps in the learning procedures and teaching. This could be due to a shortage of knowledge or poor technical assistance from colleges. Therefore, it is deemed important to educate teachers about modern teaching and training technology. Podcast is an example of emerging technologies that students have seen in a constructive light in connection with this research. Consequently, it is worth attempting to introduce podcasting particularly in English in the teaching and learning process. The aim is easy to listen to podcast. For students to expose themselves to language, particularly English, Podcast may act as an open tool. In this report, the results indicated that most students looked favourably at podcasting. Most of the research on this subject confirmed this result. The results of the review found that the majority of research indicate a constructive approach to podcasting by students. In addition, some students agreed, based on the interview, that they have improved their listening abilities with podcasting. Furthermore, the results indicate that podcast has motivated students to study English. Podcast introduced them with fascinating topics and simple indigenous pronunciation that improves learning. In particular in the e-learning world, podcast inspired students to read. Compared to traditional documents that teachers normally use, podcast gives students additional rewards and enthusiasm.

\section{References}

Arai, Zhang, Y., Lin, C. H., Zhang, D., \& Choi, Y. (2017). Motivation, strategy, and English as a foreign language vocabulary learning: A structural equation modelling study. British Journal of Educational Psychology, 87(1), 57-74.

Zou, L., \& Zhou, Y. (2017). A study of English vocabulary learning strategies used by ethnic minority students in Leshan Normal University, Sichuan, China. Theory and Practice in Language Studies, 7(6), 468-472.

Mokhtar, A. A., Rawian, R. M., Yahaya, M. F., Abdullah, A., \& Mohamed, A. R. (2017). Vocabulary learning strategies of adult ESL learners. The English Teacher, 12.

Hao, Y., Lee, K. S., Chen, S. T., \& Sim, S. C. (2019). An evaluative study of a mobile application for middle school students struggling with English vocabulary learning. Computers in Human Behavior, 95, 208-216.

Widyastuti, I., \& Kusuma, A. (2019, November). The Mapping of the Primary School English Vocabulary Learning Strategies: Volsques Questionnaire. In PROCEEDINGS: THE INTERNATIONAL CONFERENCE ON TECHNOLOGY, EDUCATION, AND SCIENCE (Vol. 1, No. 1, pp. 105-108).

Chen, C. M., Chen, L. C., \& Yang, S. M. (2019). An English vocabulary learning app with self-regulated learning mechanism to improve learning performance and motivation. Computer Assisted Language Learning, 32(3), 237-260.

O'G'Li, U. Z. B., \& Muzaffarovna, A. N. (2019). Problems encountered in learning English for specific purposes. Вопросы науки и образования, (3 (47)).

Asyiah, D. N. (2017). The vocabulary teaching and vocabulary learning: Perception, strategies, and influences on students' vocabulary mastery. Jurnal Bahasa Lingua Scientia, 9(2), 293-318.

Afzal, N. (2019). A study on vocabulary-learning problems encountered by BA English majors at the university level of education.

Woottipong, K. THE EFFECTIVENESS OF THE USE OF VIDEO PODCAST LESSONS AND MOODLE ON LANGUAGE LEARNING.

Al-Ahdal, A. (2020). Overcoming pronunciation hurdles in EFL Settings: An evaluation of podcasts as a learning tool at Qassim University Saudi Arabia. Asian EFL Journal Research Articles, 27.

Yi-qiu, W. A. N. G. (2018). Study on the Intention of College Students' Using Video Podcast to Assist EFL Learning. Journal of Harbin University.

Shahid, S. H., \& Ali, Z. (2018). Finding the best length of video-podcasts: Effects of varied numbers of videopodcast used on listening comprehension of Saudi undergraduates. International Journal of Novel Research in Education and Learning, 4(5), 19-31.

Sodikin, R. M. H. (2020). The use of English Podcast Video in practicing pronunciation skill of stressed word in e-Learning class (Doctoral dissertation, UIN Sunan Gunung Djati Bandung).

Killingback, C., Ahmed, O., \& Williams, J. (2019). 'It was all in your voice'-Tertiary student perceptions of alternative feedback modes (audio, video, podcast, and screencast): A qualitative literature review. Nurse education today, 72, 32-39.

Dmytriieva, O. (2018). Using podcasts for teaching English (through the example of "English with Oleseya" radio English lessons and podcasts).

Yugsán-Gómez, W., Mejia-Gavilanez, P., Hidalgo-Montesinos, K., \& Rosero-Morales, A. (2019). Podcasts as an Educational Tool for EFL Educators. Revista d'Innovació i Recerca en Educació, 12(1), 1. 
Schenck, A. D. (2018). An Investigation of the Relationship between Grammar Type and Efficacy of FormFocused Instruction. Online Submission.

Miyamoto, E. E. A Form-Focused Approach to Communication in English.

Kisselev, O., Dubinina, I., \& Polinsky, M. (2020). Form-Focused Instruction in The Heritage Language Classroom: Toward Research-Informed Heritage Language Pedagogy. In Frontiers in Education (Vol. 5, p. 53). Frontiers.

Piggott, L. E. B. (2019). First meaning then form: a longitudinal study on the effects of delaying and reducing explicit form-focused instruction for young adolescent EFL learners (Doctoral dissertation, LOT).

Storch, N. (2018). Meaning - Focused Versus Form - Focused Instruction. The TESOL Encyclopedia of English Language Teaching, 1-6.

Alahmad, M. (2019). The Role of Form-Focused Instruction on Foreign Language Learners. Budapest International Research and Critics in Linguistics and Education (BirLE) Journal, 2(4), 44-53.

Curado Fuentes, A. B. (2017). Form-focused data-driven learning for grammar development in ESP contexts.

Scotland, J. (2021). The efficacy of collaboratively completing form-focused tasks: A research synthesis. Working Collaboratively in Second/Foreign Language Learning, 35-58.

Oba, T. (2019). Optimal Grammar Instruction in Second Language Classrooms: Theoretical and Practical Perspectives of Form-Focused Instruction. Gakuen, (946), 1-9.

Elgort, I., Candry, S., Boutorwick, T. J., Eyckmans, J., \& Brysbaert, M. (2018). Contextual word learning with form-focused and meaning-focused elaboration. Applied Linguistics, 39(5), 646-667.

Afshar, H. S. (2021). Task-related focus-on-forms foreign language vocabulary development: Focus on spoken form and word parts. System, 96, 102406.

Franciosi, S. J. (2017). The effect of computer game-based learning on FL vocabulary transferability. Educational Technology \& Society, 20(1), 123-133.

Ma, Q. (2017). Technologies for teaching and learning L2 vocabulary. The handbook of technology and second language teaching and learning, 45-61.

Lee, J. S. (2019). Informal digital learning of English and second language vocabulary outcomes: Can quantity conquer quality?. British Journal of Educational Technology, 50(2), 767-778.

Elgort, I. (2017). Technology-mediated second language vocabulary development: A review of trends in research methodology. calico journal, 35(1), 1-29.

González-Fernández, B., \& Schmitt, N. (2017). Vocabulary acquisition. The Routledge handbook of instructed second language acquisition, 280-298.

Rodgers, M. P., \& Webb, S. (2020). Incidental vocabulary learning through viewing television. ITLInternational Journal of Applied Linguistics, 171(2), 191-220.

Viera, R. T. (2017). Vocabulary knowledge in the production of written texts: a case study on EFL language learners. Revista Tecnológica-ESPOL, 30(3). 